\title{
Polyamic Acid Nanofibers Produced by Needleless Electrospinning
}

\author{
Oldrich Jirsak, ${ }^{1}$ Petr Sysel, ${ }^{2}$ Filip Sanetrnik, ${ }^{1}$ Jakub Hruza, ${ }^{1}$ and Jiri Chaloupek1 \\ ${ }^{1}$ Nonwoven Department, Textile Engineering Faculty, Technical University of Liberec, Halkova 6, 46117 Liberec, Czech Republic \\ ${ }^{2}$ Department of Polymers, Institute of Chemical Technology, Technicka 5, 16628 Prague 6, Czech Republic
}

Correspondence should be addressed to Oldrich Jirsak, oldrich.jirsak@tul.cz

Received 17 March 2010; Accepted 16 June 2010

Academic Editor: Xiaogong Wang

Copyright ( $) 2010$ Oldrich Jirsak et al. This is an open access article distributed under the Creative Commons Attribution License, which permits unrestricted use, distribution, and reproduction in any medium, provided the original work is properly cited.

\begin{abstract}
The polyimide precursor (polyamic acid) produced of 4, $4^{\prime}$-oxydiphthalic anhydride and $4,4^{\prime}$-oxydianiline was electrospun using needleless electrospinning method. Nonwoven layers consisting of submicron fibers with diameters in the range about $143-470 \mathrm{~nm}$ on the polypropylene spunbond supporting web were produced. Filtration properties of these nanofiber layers on the highly permeable polypropylene support—namely filtration effectivity and pressure drop-were evaluated. Consequently, these polyamic acid fibers were heated to receive polyimide nanofibers. The imidization process has been studied using IR spectroscopy. Some comparisons with the chemically identical polyimide prepared as the film were made.
\end{abstract}

\section{Introduction}

Aromatic polyimides (PIs), one of the important group of high-performance polymers, are popular in many technological applications (e.g., (micro)electronics, aviation industry, separation membranes) due to their very good chemical, mechanical, and dielectric resistance in the broad temperature interval (from -150 to $250^{\circ} \mathrm{C}$ ) [1].

PIs are traditionally synthesized in two steps. The final product is often prepared by thermal solid-state imidization of a two- or one-dimensional shape of the polyimide precursor (polyamic acid (PAA)). The thermal exposition results in the formation of the thin (self-supported) polyimide film or fiber. The first step-preparation of PAA—comprises the reaction of an aromatic diamine with an aromatic dianhydride in aprotic polar solvents (e.g., N-methyl-2pyrrolidone, N,N-dimethylformamide) [2].

Polyimide fibers varying in their composition can be prepared by the dry or wet spinning of the PAA solution followed by thermal transformation (including drawing) of PAA fibers into PI ones. These products show an overall stability (e.g., heat, nuclear and UV radiation resistance, against mechanical stress and a lot of chemicals). They have also found end uses in protective clothing and filter bags [3-5].
The electrostatic spinning (ES) is a useful method to produce nonwoven layers of submicron fibers [6]. PI nanofibers are producable via ES of PAA and subsequent imidization [69]. Nah et al. [6] prepared ultrafine fibers based on pyromellitic acid and 4,4'-oxydianiline with the diameter ranged from a few tens of nanometers to several micrometers. A rectangular cross section was observed in the case of submicron fibers. Ultrafine PI fibers containing silver nanoparticles were prepared from PAA(pyromellitic dianhydride-4, 4' oxydianiline)/trifluoroacetylacetonato)silver(I) mixture. The average diameter of PI fibers decreased with the silver concentration $(200,180$, and $60 \mathrm{~nm}$ at the silver concentration 0,2 , and 7 wt.\%, resp.) [7]. Chen et al. [7] found an ultimate tensile strength of $1.7 \mathrm{GPa}$, axial tensile modulus of $13 \mathrm{GPa}$, and ultimate strain of $3 \%$ for the PI fibers based on $3,3^{\prime}, 4,4^{\prime}$-biphenyltetracarboxylic dianhydride and 1,4-phenylenediamine whose diameter was around $300 \mathrm{~nm}$. The US patent [8] is devoted to the thermal conversion of PI nanofibers, having a diameter about $200 \mathrm{~nm}$, based on pyromellitic dianhydride and $4,4^{\prime}$-oxydianiline (under triethylamine catalysts) to carbon nanofibers. The method for manufacturing polyimide-based carbon nanofiber electrode and/or carbon nanotube composite electrode is also given in this patent. 


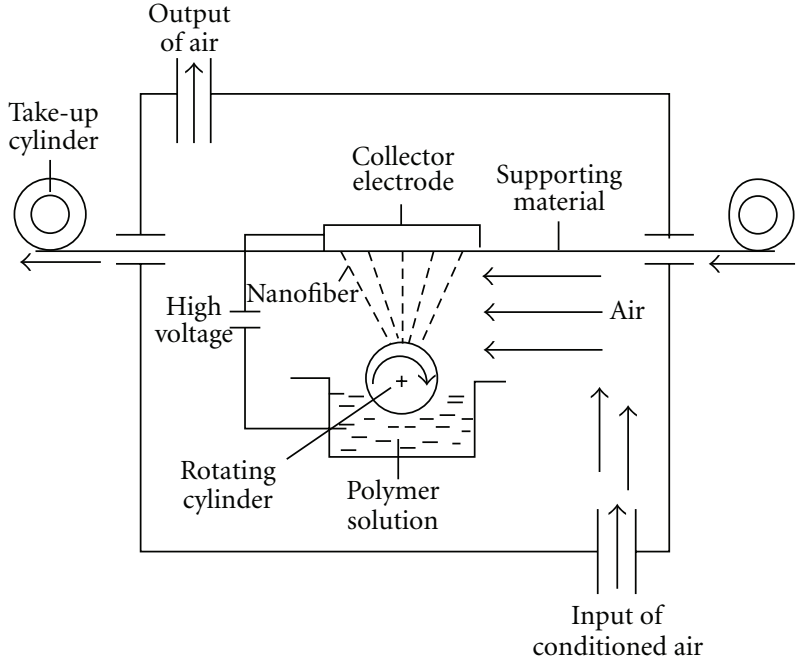

(a)

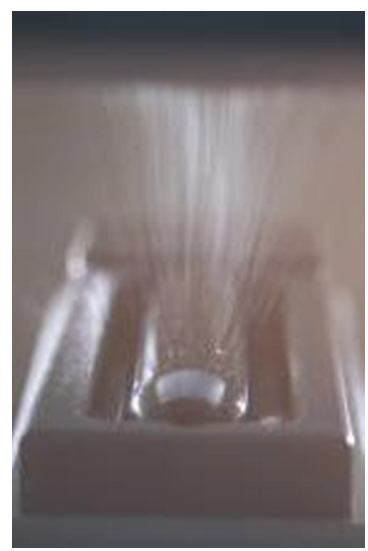

(b)

FIGURE 1: Schematic diagram (a) and photograph (b) of roller electrostatic spinner.<smiles>CCC(C)NC(=O)c1cc(C(=O)O)c(C(=O)O)cc1C(=O)O</smiles><smiles>CCc1ccc(Oc2ccc(C)cc2)cc1</smiles>

(a)<smiles>CCCC(C)(C)NC(=O)c1ccc(Oc2ccc(C(=O)O)c(C(=O)O)c2)cc1C(=O)O</smiles><smiles>CCc1ccc(Oc2ccc(C)cc2)cc1</smiles>

(b)<smiles>CCNC(=O)c1ccc(Oc2ccc(C(=O)O)c(C(=O)O)c2)cc1C(=O)O</smiles><smiles>CCc1ccc(C(C)(C)c2ccc(C(C)(C)c3ccc(C)cc3)cc2)cc1</smiles>

(c)

Figure 2: Chemical structures of (a) PAA(PMDA-ODA), (b) PAA(ODPA-ODA), and (c) PAA(ODPA-BIS P).

Nevertheless, common ES techniques based on the use of a syringe [6-9] produce nanofiber layers in quantities of approximately $0.1-1$ gramms per hour. Needleless electrospinning [10] allows industrial-scale production of nanofibers. Therefore, the aim of this work is the study of the possibility and conditions of PAA nanofibers production via a needleless electrospinning method. These fibers were tested in such applications where their mechanical and chemical stability is sufficient. Their transformation into PI nanofibers was also monitored. The PI film on the same monomer base was used for comparison of the transformation of PAA into PI and thermal stability of final products.

\section{Experimental}

$4,4^{\prime}$-Oxydiphthalic anhydride (ODPA) was heated to $170^{\circ} \mathrm{C}$ for $5 \mathrm{~h}$ in a vacuum before use. 4,4'-Oxydianiline (ODA) (both Aldrich, Czech Republic) was used as received. 


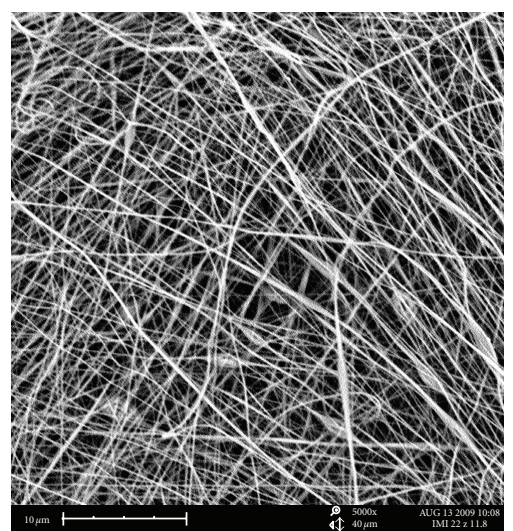

(a)

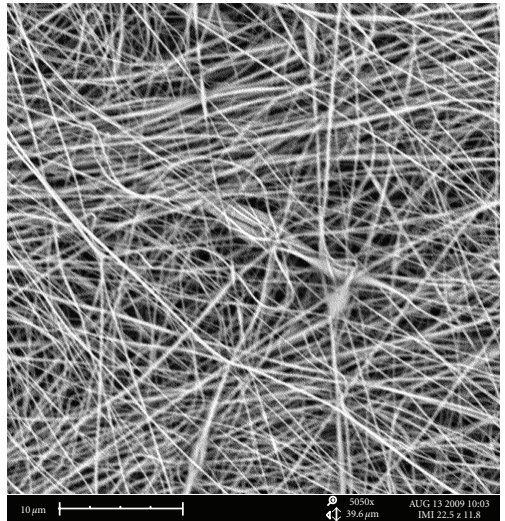

(b)

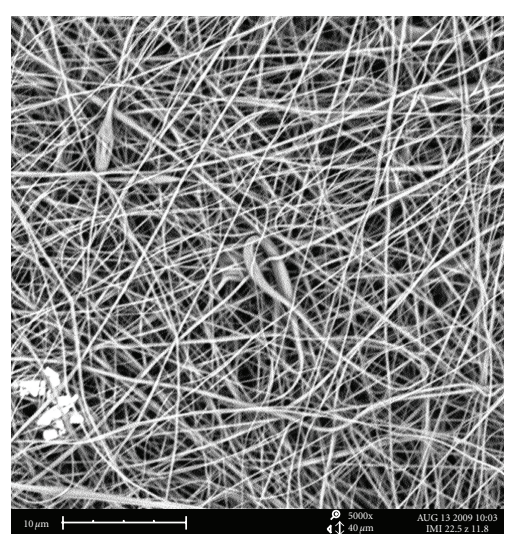

(c)

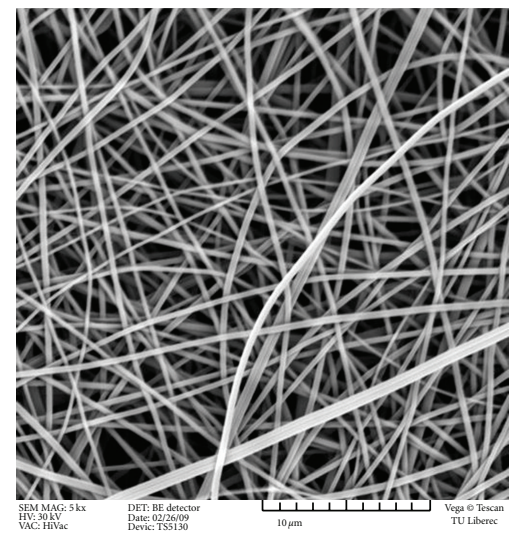

(d)

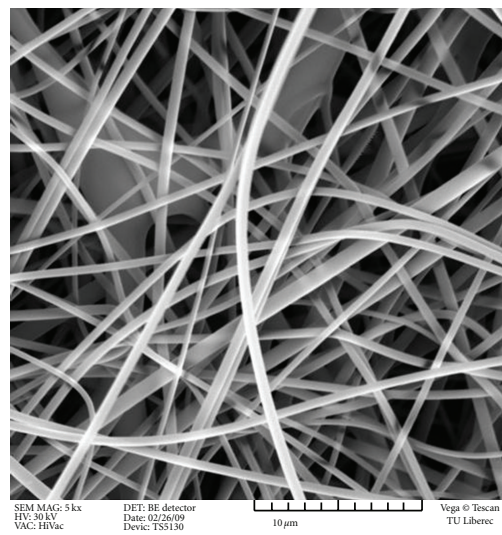

(e)

Figure 3: SEM pictures of the PAA nanofiber layers: (a) 21.5, (b) 22, (c) 22.5, (d) 24, and (e) $26 \mathrm{wt} \%$.

N,N-Dimethyformamide (DMF) (Merck, Czech Republic) was distilled under vacuum over phosphorus pentoxide and stored in an inert atmosphere.

The PAA with an uncontrolled number-average molecular weight was prepared in a $1000 \mathrm{ml}$ three-necked flask equipped with a mechanical stirrer and a nitrogen inlet/outlet. (All glassware was dried for $3 \mathrm{~h}$ prior to use.) After diamine (ODA) dissolution in a portion of DMF, an equimolar amount of ODPA together with remaining amount of DMF was placed into the flask $(22-28 \mathrm{wt} \%)$ solution of PAA in DMF). The reaction was allowed to proceed at room temperature for $24 \mathrm{~h}$.

The solutions of PAA were electrospun using a roller electrospinner [10] on polypropylene spunbond supporting web with an areal weight of $18 \mathrm{~g} \mathrm{~m}^{-2}$. The principle of spinning device is shown in Figure 1. The resulting thin layer of PAA fibers was kept (thermally imidized) at $60^{\circ} \mathrm{C}$ for $1 \mathrm{~h}$, $100^{\circ} \mathrm{C} / 1 \mathrm{~h}, 150^{\circ} \mathrm{C} / 1 \mathrm{~h}, 200^{\circ} \mathrm{C} / 2 \mathrm{~h}$, and $230-300^{\circ} \mathrm{C} / 1 \mathrm{~h}$.

In the case of the film, the $10 \mathrm{wt} . \%$ solution of PAA(ODPA-ODA) in DMF was spread onto a glass substrate. The resulting thin layer was kept at gradually increased temperatures, finally at $230^{\circ} \mathrm{C}$ for $1 \mathrm{~h}$ (see above). The thickness of the transparent self-standing film obtained was about $30 \mu \mathrm{m}$.
The dynamic viscosity of PAA solutions was measured in DMF using a Malvern rheometer at $25^{\circ} \mathrm{C}$ and the intrinsic viscosities of PAA in DMF at $25^{\circ} \mathrm{C}$ using an Ubelohde viscometer. IR spectra of PAA and PI were recorded on a Nicolet 6700 spectrometer. The nanofiber layers of PAA were analyzed using a scanning electron microscope (SEM) VEGA TS 5130 (Tescan, Brno, Czech Republic). Using the image analysis Lucia, diameters of 200 nanofibers were measured in every SEM photograph and arithmetic average calculated. Filtration properties of the PAA nanofiber layers with an areal weight of $2 \mathrm{~g} \mathrm{~m}^{-2}$ were measured using an air dispersion of sodium chloride particles having a dimension from 0.02 to $2.0 \mu \mathrm{m}$ using a Bench Mounting Rig, type 1100 P (Moore's, Ltd., U.K.) according to BS 4400, "Method for Sodium Chloride Particulate Test for Respirator Filters" at the air velocity of $5 \mathrm{~m} \mathrm{~min}^{-1}$. Dynamic thermogravimetric measurements (TGA) of PI were performed in nitrogen using a TG-750 Stanton-Redcroft (heating rate $10^{\circ} \mathrm{C} \mathrm{min}^{-1}$ ).

\section{Results and Discussion}

Three PAA(s) of uncontrolled molecular weight varying in their chemical composition were tested as materials for ES in this work. The chemical structures of PAA based on 


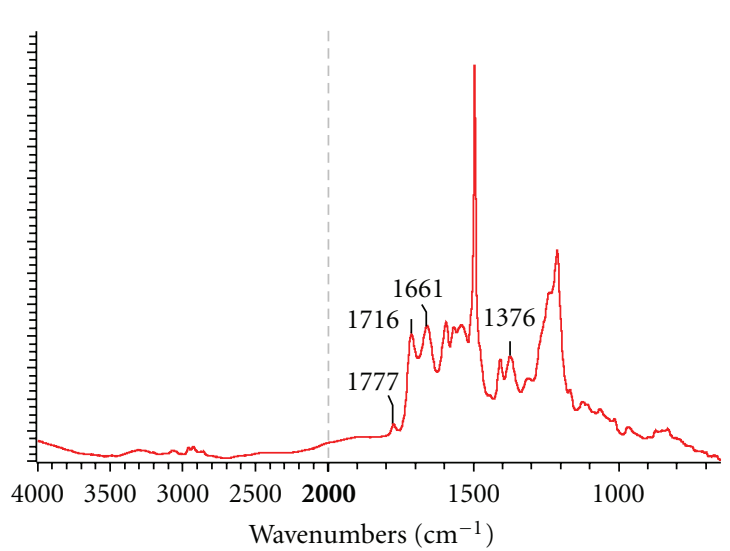

(a)

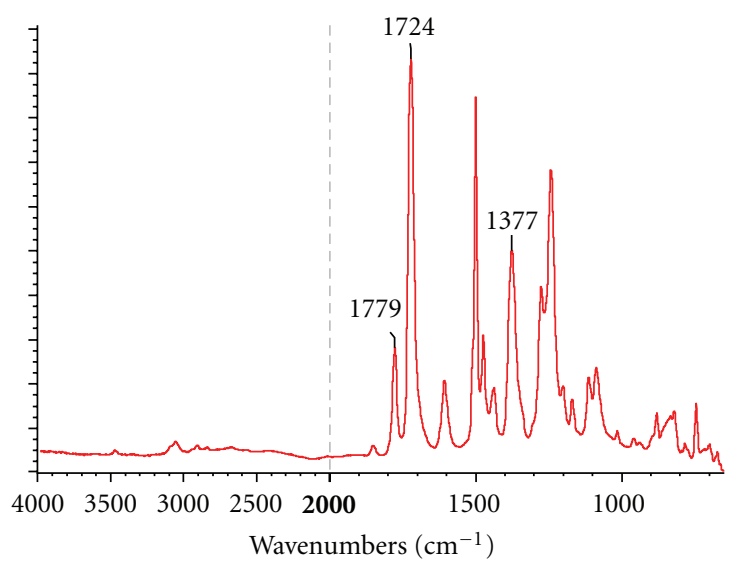

(c)

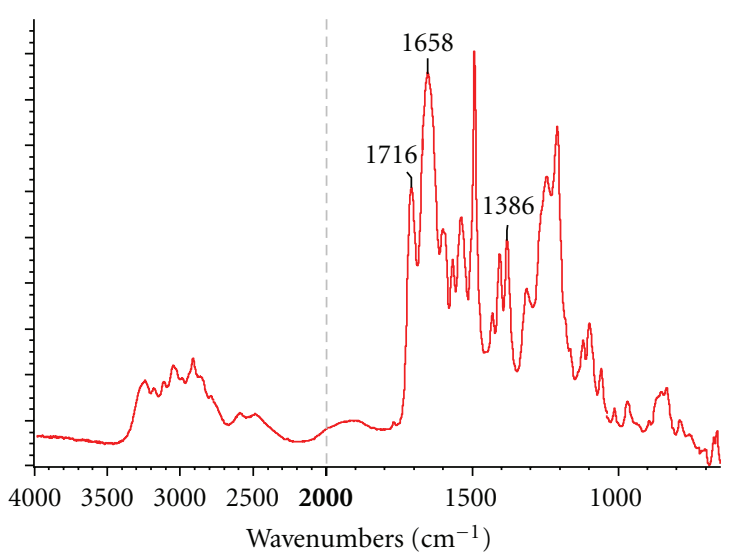

(b)

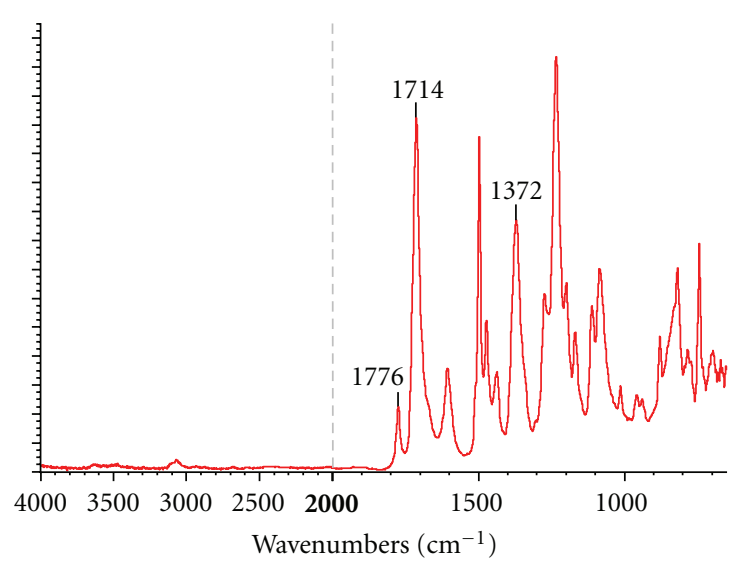

(d)

FIGURE 4: IR spectra of PAA(ODPA-ODA) in the form (a) nanofibre nonwoven layer, (b) solution in NMP and corresponding PI in the form (c) nanofiber nonwoven layer, and (d) film.

pyromellitic dianhydride (PMDA) and ODA (PAA(PMDAODA)), ODPA and ODA (PAA(ODPA-ODA)), and ODPA and 1,4-bis(4-amino-1,1-dimethylbenzyl)benzene (BIS P) (PAA(ODPA-BIS P)) are summarized in Figure 2.

The PAA(ODPA-ODA) only suited from the point of both its spinnability and quality (appearance) of the fibers. The flexible ether bridge in the ODPA molecule can favourably influence the rigidity/flexibility ratio of final fibers. The use of DMF with a lower boiling point $\left(153^{\circ} \mathrm{C}\right)$ as the solvent showed more advantageous for this purpose in comparison with $\mathrm{N}$-methyl-2-pyrrolidone (b. p. $202^{\circ} \mathrm{C}$ ) which is frequently used in polyimide syntheses [1].

The traditional concentration of PAA in the range of $10-15$ wt.\% $[1,3]$ was too low from the point of the PAA spinnability via a needless ES. The concentrations in the interval 21.5-26 wt.\% were shown suitable for this purpose. It is known that the molecular weight of PAA is dependent on the solution concentration [3]. This assumption was supported by the different value of intrinsic viscosity $\eta$ for PAA(ODPA-ODA) prepared in $10 \mathrm{wt} . \%$ solution $(\eta=$ $\left.33.7 \mathrm{ml} \mathrm{g}^{-1}\right)$ in comparison with that prepared in $28 \mathrm{wt} . \%$ solution $\left(\eta=28.8 \mathrm{ml} \mathrm{g}^{-1}\right)$. The dynamic viscosity of $26 \mathrm{wt} . \%$ solution of PAA(ODPA-ODA) was $720 \mathrm{mPa}$ s at $25^{\circ} \mathrm{C}$.
The spinning process parameters were optimized with respect to a spinnability, regularity of nanofiber layer, throughput, and time-related process stability as follows [4]: spinning roller-barbed roller $(4 \mathrm{rpm})$, distance rollercollector $(160 \mathrm{~mm})$, relative humidity $21 \%$, temperature $20.5^{\circ} \mathrm{C}$, and voltage between electrodes $80 \mathrm{kV}$. The nanofibre diameter (and filtration properties also) depends usually on a solution concentration. Therefore, the solution concentration was selected as the independent variable of the electrospinning process. The PAA solution concentrationnanofibre diameter relationship is documented in Table 1 and Figure 3. The data show that the fiber diameters can be controlled by the concentration of the PAA solution. The average diameter of the fiber prepared from $22 \mathrm{wt} . \%$ solution is about three-fold smaller in comparison with that from 26 wt.\% solution. It is also obvious from Table 1 that the finer fibers provide the layers with a better filtration efficiency and larger pressure drop. Thus, the filtration properties can be controled and optimized.

The polyimide precursor (PAA) was transformed into PI using thermal exposition. Both precursors and final products were analyzed by IR spectroscopy. Spectra of the PAA(ODPAODA) in the form of nanofiber nonwoven layer or solution 


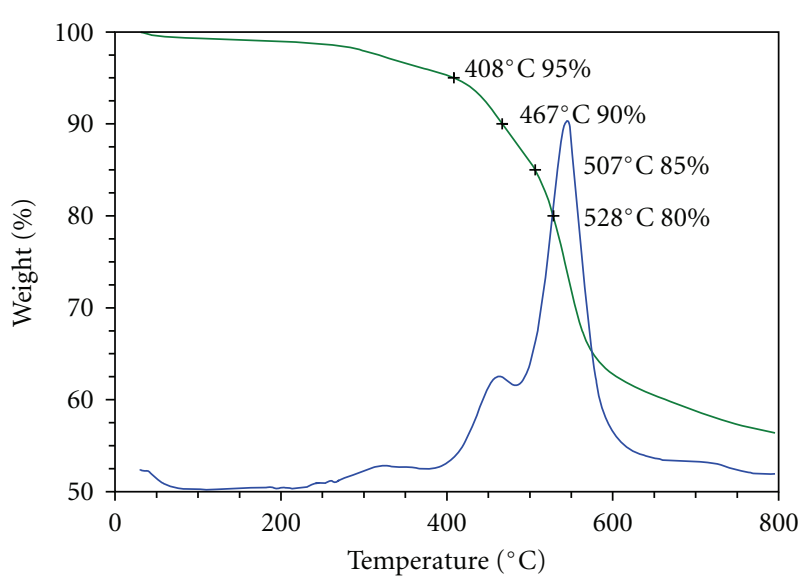

(a)

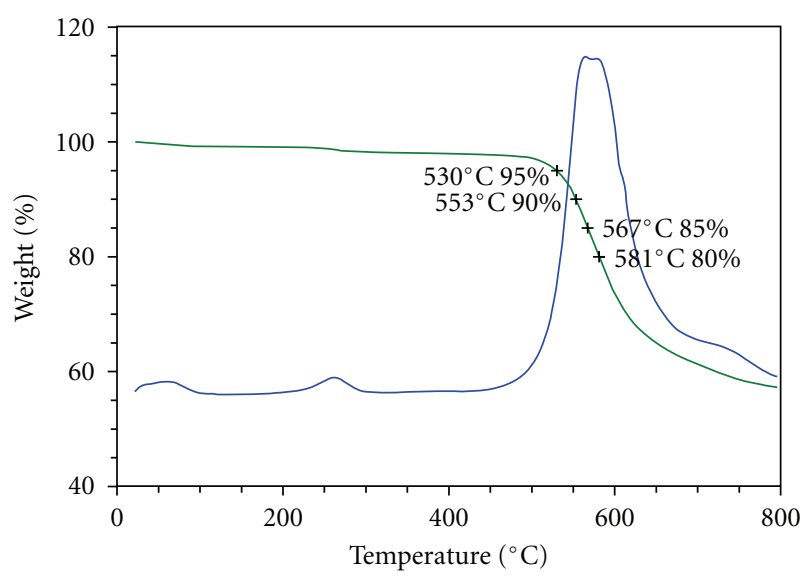

(b)

FIgURE 5: Thermogravimetric records of PI fibre (a) and PI film (b) (temperatures $\left({ }^{\circ} \mathrm{C}\right.$ ) corresponding to $5,10,15$, and $20 \mathrm{wt} \%$ weight loss are included).

TABLE 1: Dependence of the fiber diameters and filtration properties of PAA nanofibers.

\begin{tabular}{llll}
\hline $\begin{array}{l}\text { Solution } \\
\begin{array}{l}\text { concentration } \\
(\text { wt.\%) }\end{array}\end{array}$ & $\begin{array}{l}\text { Average fiber } \\
\text { diameter }(\mathrm{nm})\end{array}$ & $\begin{array}{l}\text { Filtration } \\
\text { efficiency }(\%)\end{array}$ & $\begin{array}{l}\text { Pressure drop } \\
(\mathrm{Pa})\end{array}$ \\
\hline 21.5 & 143 & 97.5 & 94 \\
22 & 162 & 94.6 & 90 \\
22.5 & 199 & 92.3 & 89 \\
24 & 318 & 81.0 & 70 \\
26 & 475 & 76.3 & 64 \\
\hline
\end{tabular}

and corresponding PI in the form of nanofiber nonwoven layer or film - using the final imidization step $1 \mathrm{~h} / 230^{\circ} \mathrm{C}$ are collected in Figures 4(a)-4(d). The absence of the band at $1661 \mathrm{~cm}^{-1}$ (fibre) or $1658 \mathrm{~cm}^{-1}$ (solution) (amide groups of PAA-see the spectra designated as Figures 4(a) and 4(b) in the spectra of PI nanofiber (Figure 4(c)) or PI film
(Figure $4(\mathrm{~d})$ ) confirms the practically total transformation of the precursor to PI. Therefore, it is obvious that this procedure including the final heating $1 \mathrm{~h} / 230^{\circ} \mathrm{C}$ is sufficient for the practically full transformation of PAA to PI both in the form of nanofiber or film. The absorption bands at 1779$1724 \mathrm{~cm}^{-1}$ (fiber) or $1776-1714 \mathrm{~cm}^{-1}$ (film) (symmetric and asymmetric stretching of the ring carbonyl groups) and $1377 \mathrm{~cm}^{-1}$ (fiber) or $1372 \mathrm{~cm}^{-1}$ (film) (stretching of the ring $\mathrm{C}-\mathrm{N}$ bond) are distinct in the spectra of final products and characterize the formation of imide structures Figures $(4(\mathrm{c})-4(\mathrm{~d}))$. The maxima of these bands in IR spectra are at similar wavenumbers for the PI nanofibers finally transformed $1 \mathrm{~h} / 250^{\circ} \mathrm{C}$ or $1 \mathrm{~h} / 300^{\circ} \mathrm{C}$ (see Section 2). These bands of a low intensity characterizing PI structure are also observable in the spectra of PAA fiber and PAA solution (Figures 4(a) and 4(b)). Based on our previous experience (e.g., [2]), they seem to be more significant than those from PAA on the same monomer basis but with a lower solution concentration (about $10 \mathrm{wt} . \%$ ). The PAA synthesis from a dianhydride and a diamine is the exothermic reaction and the amount of evolving heat increases with the monomer concentration. Then, it could be one reason of the higher imidization level of PAA prepared in highly concentrated solutions.

The thermogravimetric records and the thermal stabilities (evaluated as the temperatures corresponding to 5$20 \mathrm{wt} . \%$ loss during thermogravimetric analysis with a temperature gradient of $10^{\circ} \mathrm{C} \mathrm{min}^{-1}$ ) are collected in Figure 5 for the PI nanofibre layer (a) and PI film (b).

By using this instrumental technique, the PI in the form of film appears more thermally stable than that in the form of fibre (prepared from $26 \mathrm{wt} . \%$ PAA solution in DMF). This apparently higher thermal stability of the PI film is probably connected with its geometry (a thickness about $30 \mu \mathrm{m}$ ) in comparison with the fibre diameter (about 200-300 nm).

\section{Conclusions and Future Work}

PAAs based on ODPA and ODA having the solution concentration in the range 21.5 to $26 \mathrm{wt} \%$ were successfully electrospun using a needless electrospinning method. The average fiber diameter increases with the PAA solution concentration from 140 to $470 \mathrm{~nm}$. The filtration efficiency and pressure drop of PAA nanofibre layers decreased with increasing fibre diameter. They were transformed to polyimide nonwoven layers by thermal treatment. The final heating at $230^{\circ} \mathrm{C}$ for $1 \mathrm{~h}$ is sufficient for the nearly full imidization. Due to its geometry, the PI film based on the same monomer basis (i.e., ODPA and ODA) is more thermally stable compred to the fibre layer.

The main disadvantage of a polypropylene spunbond supporting web is its limited thermal stability. Therefore, a number of different glass woven webs were obtained and their suitability as a support of the PI layers will be evaluated. Adhesives varying in their composition (inorganic adhesives, silicones, epoxides) will be employed to improve interfacial (support-polymer) adhesion. These materials will be tested in relation to possible technological processes and filtration and mechanical properties. 


\section{Acknowledgments}

This work was supported by the Grant Agency of the Czech Republic through grant no. 104/09/1357, by the research program MSM 6046137302, and by the project 1M0554 (Research Center, TUL Liberec).

\section{References}

[1] P. M. Hergenrother, "The use, design, synthesis, and properties of high performance/high temperature polymers: an overview," High Performance Polymers, vol. 15, no. 1, pp. 3-45, 2003.

[2] P. Sysel, V. Konečná, and K. Volka, "Structure-curing relation for polyamic acids," European Polymer Journal, vol. 32, no. 3, pp. 317-320, 1996.

[3] C. E. Sroog, "Polyimides," Progress in Polymer Science, vol. 16, no. 4, pp. 561-694, 1991.

[4] L. Dai and L. Chen, "Preparation of polyimide fibers," patent no.: CN 101525783, CAN 151: 405196, Soochow University, China, 2009.

[5] X. Qiu, L. Gao, M. Ding, and F. Liu, "Method for preparing polyimide fibers," patent no.: CN 101338462, CAN 150: 193248, Changchun Institute of Applied Chemistry, Chinese Academy of Science, China, 2008.

[6] C. Nah, S. H. Han, M.-H. Lee, J. S. Kim, and D. S. Lee, "Characteristics of polyimide ultrafine fibers prepared through electrospinning," Polymer International, vol. 52, no. 3, pp. 429-432, 2003.

[7] F. Chen, X. Peng, T. Li et al., "Mechanical characterization of single high-strength electrospun polyimide nanofibres," Journal of Physics D, vol. 41, no. 2, Article ID 025308, 2008.

[8] D. W. Park, H. S. Noh, H. Nojima, T. X. Nguyen, C. H. Song, and Y. H. Lee, "Metod for manufacturing polyimidebased carbon nanofiber electrode and/or nanotube composite electrode and CDI apparatus using the electrode," patent no. US 20090107842, CAN 150: 485815, Samsung Electronics Co., Ltd., South Korea, 2008.

[9] Q. Zhang, D. Wu, S. Qi, Z. Wu, X. Yang, and R. Jin, "Preparation of ultra-fine polyimide fibers containing silver nanoparticles via in situ technique," Materials Letters, vol. 61, no. 19-20, pp. 4027-4030, 2007.

[10] O. Jirsak, F. Sanetrnik, D. Lukas, V. Kotek, L. Martinova, and J. Chaloupek, "Process and apparatus for producing nanofibers from polymer solution electrostatic spinning," patent no.: EP 1673493, CAN 142:393731, Technicka Univerzita v Liberci, Czech Republic, 2009. 

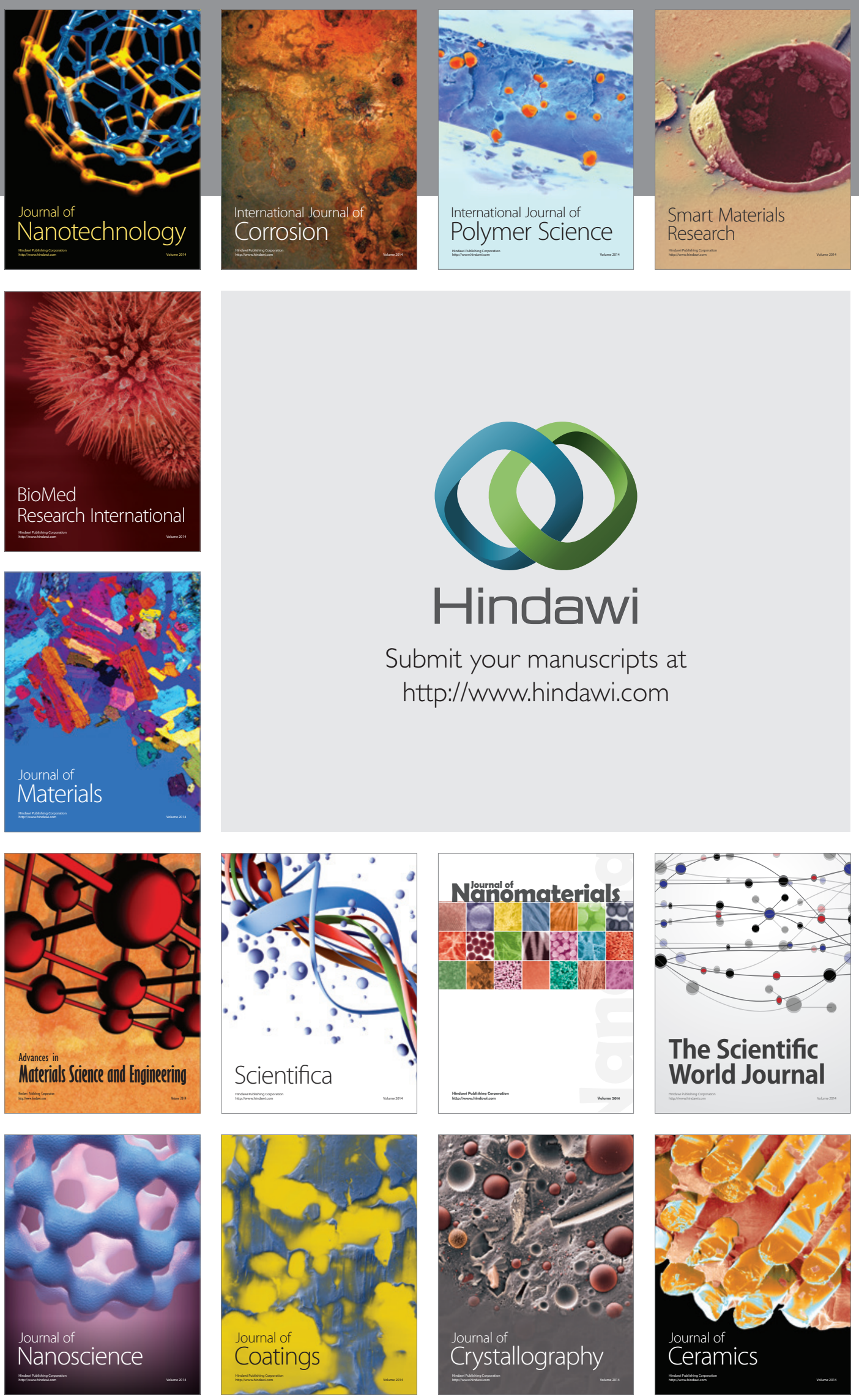

The Scientific World Journal

Submit your manuscripts at

http://www.hindawi.com

\section{World Journal}

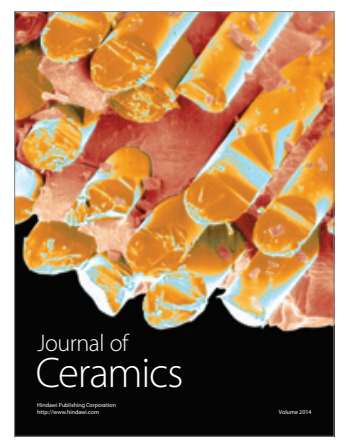

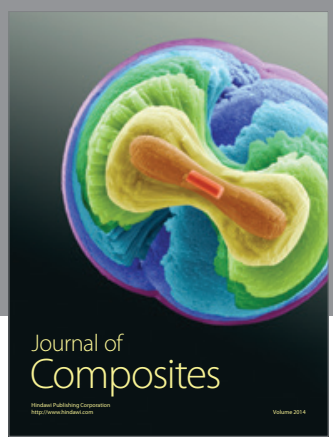
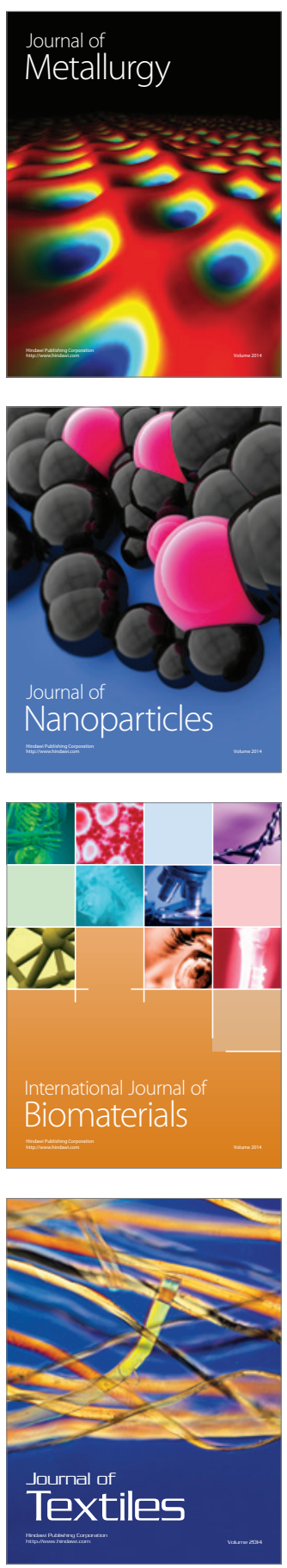